seems now to have abated, yet who will answer for what may happen in the immediate future. One thing is certain : if cholera should again reach Egypt let the bondholders beware. Dervishes and inundations are not the only enemies to be repelled at the cost of a million per annum. Let them spend sometbing also on sanitary assurance. The sanitary administration possesses a most efficient pelled to make bricks without straw, and often the very clar is refused to him. Allow him the necessary funds and before lon clas is refused purged of its sins against hygiene, will, with its glorious and life-giving purged of socond to none in the world for salubrity."

I am, Sirs, yours faithfully,

St. John's, Woking, June 15th, 1896. H. R. GReEne.

\section{THE CAUTERY IN OVARIOTOMY.}

To the Editors of THE LANCET.

SiRs,-In The LANCET of May 16th Mr. Tait claims that he has discovered the true principle of the cautery as used by Mr. Baker Brown and Dr. Keith. This shows such a want of memory of his own writings, and want of knowledge of the writings of others, that it seems almost beyond belief. In 1883 Mr. Tait wrote: "When he (Dr. Keith) removes the clamp, that part of the pedicle which has been embraced by it is shrivelled and translucent like parchment." Mr. Tait had therefore either seen the cautery applied or had had its mode of application explained to him. He has evidently forgotten this and also the method of application, for he speaks of great physical exertion and of the time required being twenty or thirty minutes. There is no special exertion, and when we used the cautery irons at a dull red, never a black, heat seven or eight minutes was the average time ; now, by using them at a white heat three minutes are sufficient. In Dr. Skene's work on " Diseases of Women," published in 1888 , the principle of action is described in the following words : "The object is to desiccate at least half an inch of the stump and to avoid charring it." In a paper on the Cautery in THE LANCET of April 30th, 1892, I said "the compressed part of the pedicle will, if all be satisfactory, have the appearance of a piece of horn. ..... Bleeding never occurs after the abdomen has been closed, and to prevent it at the time of operation the two essential points are the screwing up tight and the heating of the blades of the clamp." The amusing part is that Dr. Keith found out the explanation only after performing several operations on animals, and now Mr. Tait, having partially forgotten or perhaps not thoroughly understood what he described thirteen years ago, tells us that operations on animals are unnecessary. I am, Sirs, yours faithfully,

Charles-street, W., June 10th, 1896. SKENE KEITH.

\section{"ANTERIOR COLPOTOMY."}

To the Editors of THE LANCET.

Sins, - I should be glad if you would allow me to record in THE LANCET my remarks on Dr. John Phillips' paper on "Anterior Colpotomy" read at the last meeting of the Obstetrical Society. They were not forwarded owing to a failure of the post-office arrangements.

I said that the difficulty of making and keeping the vagina aseptic as set forth by Dr. Phillips seemed to me a very serious objection to the removal of intra-peritoneal disease by anterior colpotomy ; and that another important objection was the fact that, when small tumours or inflamed ovaries required operation, their removal was frequently so difficult that it was not possible to operate with any safety by anterior colpotomy, whilst the easier cases should have no mortality, except from purely accidental causes, if done by abdominal section. Under these circumstances it seemed to me that to operate on intra-peritoneal pelvic conditions through the vagina must add to the risks in all cases in which this plan might be contemplated. I should like to add that the cases in which the ablation of inflamed ovaries and tubes is required, but in which it is almost or quite impossible to completely remove these organs even when the parts have been fully exposed, are sufficiently numerous already without the operator handicapping himself by the diffculties and dangers of working through a strictly limited space of doubtful ascepticity. It seems to me certain that the plan of operating by anterior colpotomy must not only cause greater danger to the patient but that it must also lead to an increase in the number of imperfect operations. The evils of these imperfect operations do not appear in statistical tables. They can be discovered only by the study of the after-histories of cases. Personally I have performed few operations which could have been done by anterior colpotomy. I have not. performed any operation in which $I$ can believe that the slightest advantage could have been gained by adopting this method, and I have done many successfully in which an attempt to operate through the pelvic outlet would 'have ended inevitably in failure.

I am, Sirs, yours faithfully,

Portman-street, June 15th, $1896 . \quad$ JoHN D. MaLCOLM.

THE ST. JOHN AMBULANCE ASSOCIATION AND I'TS LECTURERS.

To the Editors of THE LANCET.

Sins,-The St. John Ambulance Association has, with the coöperation of the medical profession, accomplished much that is excellent, and I, like other medical men, have taken great pleasure in the work done for it. Consequently, I was not merely surprised but sorry to find this Association taking up a position in regard to the profession which has compelled me to resign my honorary membership. The matter will probably be a surprise to most if not all of the ambulance lecturers, and it seems to me of such importance that I venture to give it publicity in your columns. The facts need occupy but little space. The authorities of the local Young Women's Christian Association requested me to give them lectures on nursing. They gave me various reasons why they did not propose to form a class in connexion with the St. John Ambulance Association, among others that the pupils did not wish to enter for any examination. The request was only for two lectares, and it was at my own sug. gestion that the number was increased to six. A lady who is one of the Ambulance Brigade nurses promised both the superintendent of the Young Women's Christian Association and myself independently that she would give assistance in her private capacity. The hour of the lectures was such as not to interfere with any brigade work. To my astonishment this lady informed me later that she must withdraw from her promise because the ambulance authorities "could not give their sanction." Wishing to avoid any unpleasantness, I accepted the position and gave additional time and work to make up for the lo:s of her friendly assistance. Much to my annoyance, a few days later I was informed by a medical neighbour that the ambulance authorities were criticising my conduct in giving such lectures as unfriendly and even shabby. A letter to, and interview with, the local honorary secretary, Mrs. Colegrave, showed me that her part in the matter had merely been to carry out instructions from headquarters, so I wrote asking that I should be informed from headquarters: " 1 . Whether they consider the fact of a doctor having delivered lectures under their auspices should preclude him from doing any similar work at the request of others? 2 . On what grounds they used their influence to prevent a lady who was willing in her private capacity to give me some assistance with a nursing class from carrying out her intention?" The following reply was communicated to me (The italics, \&c., are Sir Herbert Perrott's.)

"St. John Ambulance Association, May 23rd, 1896. "Dear Mrs. Colegrave, - With reference to Dr. Carruthers' letter which you have submitted to me, my opinion is, while in the abstract ther is nothing to prevent a medical man from lecturing in accordance with the syllabus of the association whenever and wherever he pleases, the fact that he has accepted the position of honorary life member offered him in recognition of his services on behalf of the Association should tend to induce him not to give lectures on the lines of the Association except under its auspices. As superintendent of the Norwood Nursing Division you are fully within your right in forbidding one of your enrolled nursing sisters to assist in any way at lectures on the subject of first aid or nursing, whether in connexion with the Association or not. In so doing she cannot be said to be acting in her private capacity. "Yours faithfully, Herbert C. Perrotit.

"If Dr. Carruthers and the nursing sister wish to instruct classes on their own account it would be more honourable in them to resign honourable life membership and membership of the nursing division respectively. By not doing so they are leading people to infer that
they are acting under the auspices of the Association, and as their pupils will not be examined by our examiners, or get our certificates, it
is very hard on them-that is, the pupils.
H. C. P."

H. C. P."

While this letter skilfully evades a categorical reply to either of my questions, it left only one course open to me, for the postscript to all intents and purposes called upon me to resign because I had lectured to the Young Women's Christian Association class. My reply is subjoined.

" 44, Central-hill, Norwood, S.F., June 11th, 1896.

" DraR SIR,-I am much obliged for the information contained in 